\title{
Applying Educational Psychology for Spiritual Teacher Development in Thailand
}

\author{
Dr.Lampong Klomkul ${ }^{1}$, Phramaha Prasit Kaewsri ${ }^{2}$, Phrapalad Raphin Duangloi ${ }^{3}$ \\ Mahachulalongkornrajavidyalaya University, Thailand ${ }^{1,2,3}$
}

\begin{abstract}
The purposes of this research were 1 ) to study educational psychology for spiritual teacher development; 2 ) to develop an educational psychological curriculum of spiritual teachers training applying reflection process; and 3) to assess spiritual teacher development in Thailand using the educational psychological curriculum. Action research was used for research design following 4 phases of PAOR process. The target group was 120 teachers from office of the basic education commission who registered. Data were collected by using interview, observation and reflection note taking. Content analysis and analytic induction were used for data analysis. The research results were as follows: 1) Educational psychology for spiritual teacher development was the integration of reflection process and the threefold training to enhance the level of professional learning community. 2) The educational psychological curriculum of spiritual teachers training was developed into six steps. They were: knowing what to do - correcting and changing - learning from doing - leading to new understanding - acting from reflecting - thinking of innovation. 3) Spiritual teacher in Thailand was developed as a professional learning community through six steps consisted of (1) to know the role of spiritual teacher, (2) to adjust oneself followed by threefold training, (3) to learn how to be a best practice teacher, (4) to change a good attitude being spiritual teacher, (5) teaching with Buddhist integration into classroom, and (6) to create effective learning innovation.
\end{abstract}

Keywords: Professional Learning Community; Reflection process; Spiritual teacher; Teacher training; Threefold training 